\title{
Immature to Mature - A Predictable Outcome of Two Immature Incisors with 36 Months Follow-Up!
}

\author{
Neeta Surendra Padmawar'1, Viddyasagar Prabhakar Mopagar², \\ Vinay Hanumantrao Vadvadgi ${ }^{3}$, Sourabh Ramesh Joshi ${ }^{4}$, Meghna J. Padubidri ${ }^{5}$
}

1,2,4,5 Department of Paediatric \& Preventive Dentistry, Rural Dental College, Pravara Institute of Medical Sciences (Deemed to Be University), Loni, Maharashtra, India, ${ }^{3}$ Department of Periodontology, Rural Dental College, Pravara Institute of Medical Sciences (Deemed to Be University), Loni, Maharashtra, India.

\section{INTRODUCTION}

Management of non-vital immature anterior permanent teeth in children remains a challenge in paediatric dentistry and endodontics. Once the tooth becomes non-vital, root development ceases, rendering the tooth weak, and unable to withstand physiological forces of mastication. This results in a high rate of root fracture with poor prognosis in the medium to long term. Despite being endodontically treated, over $50 \%$ of such teeth will be lost in the first 10 years following trauma. Traditional endodontic treatment does not contribute to any quantitative or qualitative increase in root dimensions resulting in life-long oral disability. The advancement in the science of Endodontics - Regenerative Endodontics has revolutionized current treatment strategies in treating the immature non-vital permanent tooth which has overcome the drawbacks of traditional treatment approaches. This report provides an insight view on successful maturogenesis of immature non-vital permanent incisors by induction of intracanal bleeding along with complications endured during the process.

Regenerative endodontics is defined as "biologically based procedures designed to replace damaged structures, including dentin and root structures, as well as cells of the pulp - dentin complex". ${ }^{1}$ Continued root development and reestablishment of pulp - dentine complex can be achieved by these procedures. Two major concepts in the regenerative endodontics are guided tissue regeneration (GTR) and tissue engineering. The base of these procedures is stem cells which can differentiate into the desired tissue component, growth factors or other tissue - inducing mediators and scaffold.2

Regenerative endodontic procedure (REP) includes induction of intracanal bleeding, placement of platelet rich fibrin (PRF), and platelet rich plasma (PRP). The goals of these procedures were elimination of signs and symptoms, continued root development, apical healing, and positive response to vitality testing. But preparation of PRP and PRF requires withdrawal of blood and sight of syringe can add emotional stress to young patients.

Revascularization may be defined as the invagination of undifferentiated periodontal cells from the apical region in immature teeth. ${ }^{3,4}$ The nature of tissue formed after revascularization is not certain and can be confirmed by histological evaluation. Presence of blood supply is reliable. Revascularization considers only one facet - nature of newly formed tissue thus making term revascularization inaccurate and thus many authors disagreed with this term. ${ }^{5}$
Corresponding Author:

Dr. Neeta S. Padmawar,

Lecturer, Department of Paediatric \&

Preventive Dentistry, Rural Dental College,

Pravara Institute of Medical Sciences

(Deemed to Be University),

Loni (BK)-413736,

Maharashtra, India.

E-mail: opneeta23@gmail.com

DOI: $10.14260 /$ jemds/2021/286

How to Cite This Article:

Padmawar NS, Mopagar VP, Vadvadgi VH, et al. Immature to mature - a predictable outcome of two immature incisors with 36 months follow - up! J Evolution Med Dent Sci 2021;10(17):1356-1360, DOI: 10.14260/jemds/2021/286

Submission 14-12-2020,

Peer Review 25-02-2021,

Acceptance 04-03-2021,

Published 03-05-2021.

Copyright (C) 2021 Neeta Surendra Padmawar et al. This is an open access article distributed under Creative Commons Attribution License [Attribution 4.0 International (CC BY 4.0)] 
Wigler et al. proposed that procedures in REPs were designed to promote continued root development and apical maturation clinically as well as radiographically in necrotic immature permanent tooth, thus these should be called as maturogenesis. The basic aim of maturogenesis was continued root development and hard tissue deposition in immature permanent teeth. ${ }^{5}$

The present article discusses the clinical and radiographic follow - up of two immature non - vital permanent maxillary incisors in which maturogenesis was seen by induction of blood clot along with their complications.

\section{PRESENTATION OF CASE}

Based upon the guidelines recommended by American Association of Endodontics (AAE) 2016 dated on 6 / 8 / 2016 selection of cases was carried out and treatment was planned. ${ }^{6}$

\section{Case 1}

Nine-year-old healthy male child visited to out-patient department of Paediatric \& Preventive Dentistry with chief complaint of pain and swelling in upper left anterior region since three days. Duration of trauma with upper anterior region was six months. Intra - oral examination revealed World Health Organization (WHO) S.02.51 fracture (Fracture of crown of tooth without pulpal involvement) with permanent maxillary left central incisor (\#21). Swelling was present in labial sulcus (measuring $1 \times 2 \mathrm{~cm}$ approximately) and duration of swelling was one day with tooth \# 21. The tooth was tender on vertical percussion and was not responsive on electric pulp testing when compared to tooth \#11. The clinical diagnosis for \#21 was apical periodontitis. Intra-oral periapical radiographs (IOPA) with parallel angle technique was advised. Radiographic examination revealed incomplete root formation and measurement of apical area was more than $1.1 \mathrm{~mm}$ with \# 21 . Maturogenesis of root by inducing blot clot in the root canal was planned. The entire procedure was explained to parents with possible advantages and complications which can occur. Consent from the parent was obtained. $2 \%$ Lignocaine with adrenaline (1:80000) $(2 \%$ LIGNOX $^{\circledR}$ ) was used for anaesthetizing buccal tissue $(2 \mathrm{ml}$, labial infiltration) and palatine tissue with nasopalatine block $(0.5 \mathrm{ml})$. Emergency access opening was carried out under OptraDam (Ivoclar, Vivadent), followed by minimum hand instrumentation with intermittent copious irrigation with 20 $\mathrm{ml}$ of normal saline was carried out. Closed dressing (Cavit ${ }^{\mathrm{TM}} \mathrm{G}$, 3M; ESPE) with \#21 was given. Patient was prescribed with antibiotics (Tablet. Clavam 228.5mg; Amoxicillin 200mg and clavulanic acid $28.5 \mathrm{mg}$ - twice a day, Tab. Metronidazole 200mg thrice a day) and analgesic (Tab. Ibugesic Jr. Ibuprofen $100 \mathrm{mg}$ and Paracetamol $125 \mathrm{mg}$ ) for 5 days and was recalled. On subsequent follow - up visit after one week, intraoral swelling subsided and tooth was asymptomatic. Under rubber dam isolation, temporary dressing was removed and intracanal copious irrigation was carried out with $20 \mathrm{ml}$ normal saline. Canal was dried with paper points followed by application of bonding agent (BONDPlus ${ }^{\circledR}$, Medicept) and curing. Triple antibiotic paste (TAP) (Amoxicillin + Metronidazole + Cipro floxacillin in $1: 1: 1$ ) mixed with propylene glycol was placed with miner trioxide aggregate
(MTA) carrier inside the root canal as intracanal medicament followed by temporary restoration (CAVITTM) for three weeks. After three weeks, patient was found to be asymptomatic with completely healed intraoral inflamed gingiva. Under rubber dam, TAP dressing was removed and intra - canal bleeding was induced under local anaesthesia (2\% lignocaine without adrenaline, $2 \%$ Lox $^{\circledR}$, Neon Allopathic Pvt. limited) with over instrumentation of sterile \#25 hand $\mathrm{K}$ - file. A cotton dipped in normal saline was placed at cervical third of root canal for 5 minutes. Once clot was formed, cotton pellet was removed without disturbing the clot white MTA (PROROOT MTA, Dentsply) plug of $2-3 \mathrm{~mm}$ was placed over clot. This was followed by the placement of type II glass ionomer cement (GIC Type 2, Gold Label; GC Fuji Japan) and composite resin restoration (Flitex Z350XT,3M ESPE St. Paul, MN, USA). [Fig.1a]

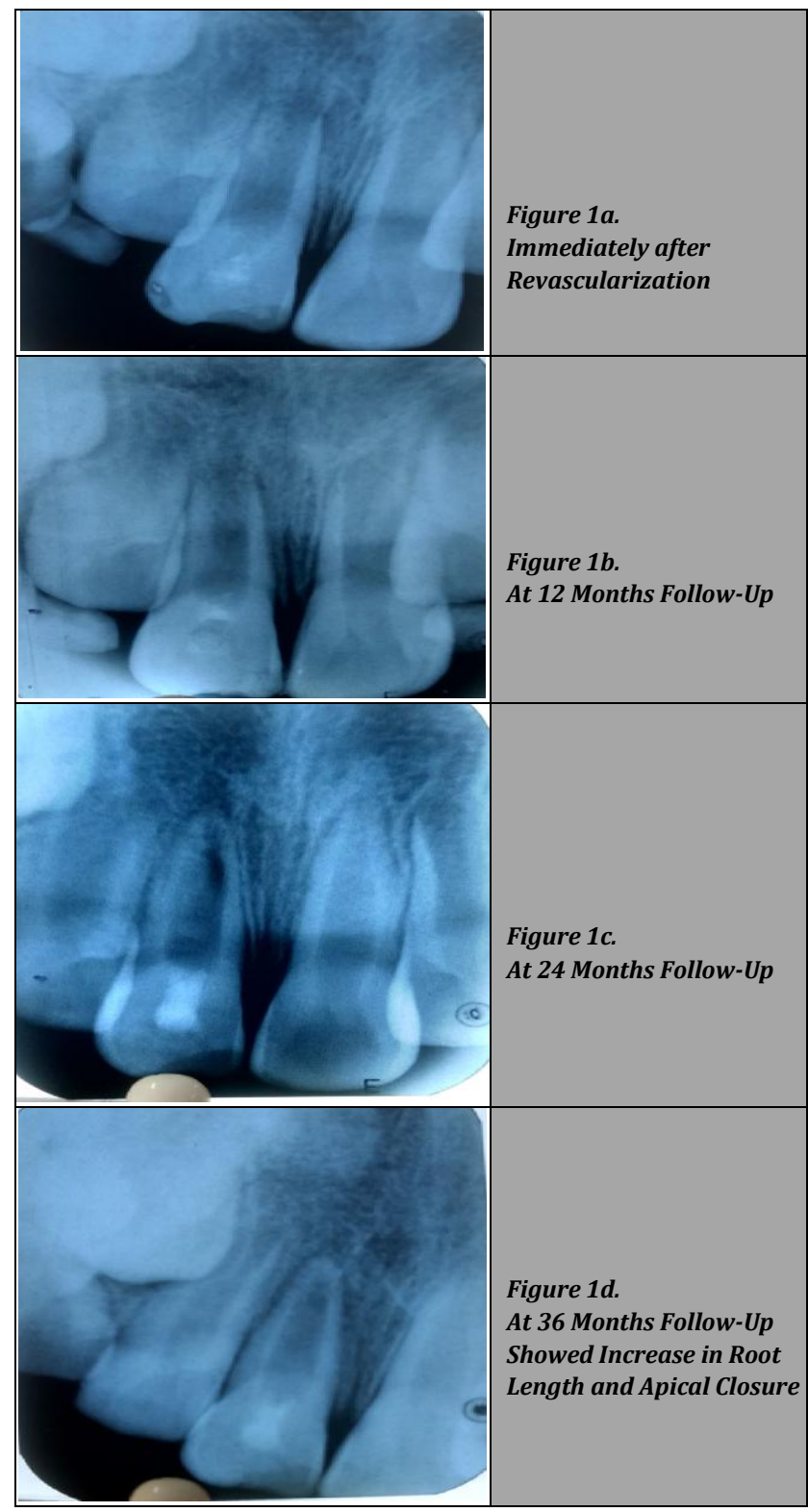

Patient was kept under observation and recalled at every 6 months interval. Clinical as well as radiographic evaluation were made at every follow - up visit. [Fig.1b, 1c, 1d] Clinically in all follow up visit tooth did not show any response during electric pulp vitality testing but radio graphically increase in root length and root dentine was observed [Fig.1b, 1c, 1d]. 
After first follow - up, tooth became darker in shade. After 36 months, polycarbonate crown was given to mask the color change.

\section{Case 2}

A healthy male child aged nine years visited to the Department of Paediatric \& Preventive Dentistry with chief complaint of pain in upper left anterior region since a week. History revealed that trauma to upper anterior region and duration was $2-3$ months. Intra-oral examination revealed trauma to permanent maxillary left central incisor (W.H.O. classification - S.02.51 Fracture of crown of tooth without pulpal involvement).

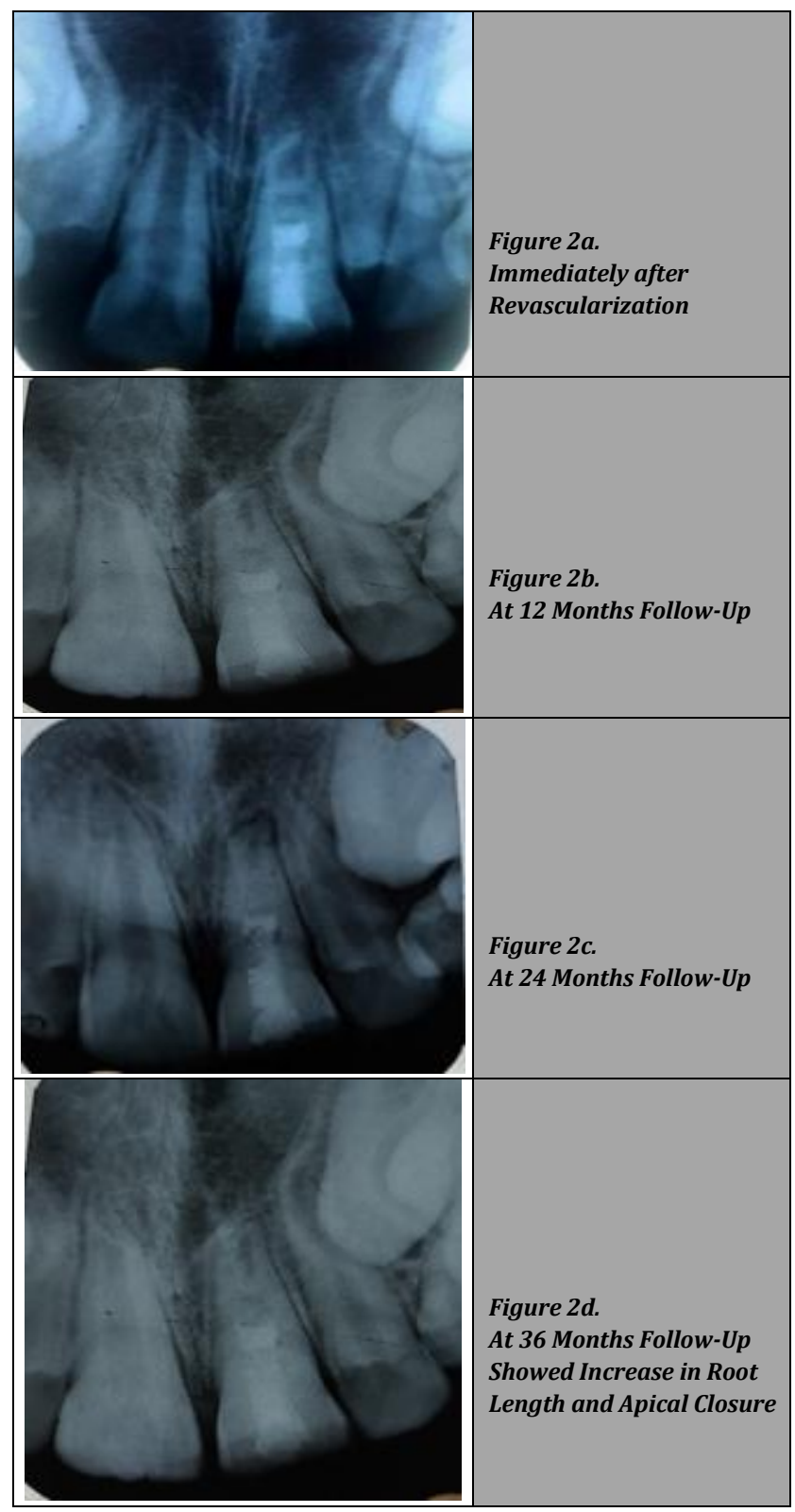

The tooth was tender to vertical percussion. Intra-oral periapical radiograph revealed incomplete root formation and diameter of apical foramina was more than $1.1 \mathrm{~mm}$ with tooth \#21. No response was observed with electric pulp testing with tooth \#21. Parent's consent for maturogenesis by induction of blood clot was obtained. In same appointment under rubber dam isolation, access opening was done with tooth \#21 followed by placement of TAP.

Prior to placement of TAP, bonding agent was applied to access cavity opening. Patient was prescribed analgesic (Tab.1, Ibugesic Jr. - Ibuprofen 100mg and Paracetamol 125mg). After 3 weeks, induction of blood clot was carried out clinically which was similar to Case 1 [Fig. 2a]. Patient was followed up every six months. In each visit, patient was clinically and radiographically evaluated.

[Fig 2b, 2c, 2d] After 24 months follow - up, tooth \#21 showed slight change in hue of crown and showed delayed response to electric pulp testing as compare to \#11,22. Composite veneer was advised but parents were reluctant. Radiographically increase in root length and root dentine thickness was observed. [Fig. 2c]. After 36 months, tooth became more darker in color and hence polycarbonate crown was delivered. In this visit, radiographic examination revealed continued root development. [Fig. 2d]. In both cases we could not do Cone Beam Confocal Tomography (CBCT) due to financial limitations of patients.

\section{DISCUSSION OF MANAGEMENT}

In 1992, Cvek $^{7}$ classified root development in four stages stage I - less than 1 / 2 of root formation with open apex, stage II - 1 / 2 root formation with open apex and stage III - 2 / 3 of root development with open apex, stage IV - nearly completed root formation with open apex, stage $\mathrm{V}$ - closed apical foramen and completed root development. Apexification will not contribute to increase in root length or root dentin thickness in stage I, II, III of above classification, so they are best suited for REPs and stage IV cases can be treated either with REPs or apexification - MTA / calcium hydroxide. Our both cases were in stage II of Cvek's classification which were ideal for REPs.

AAE recommends that apical diameter should be $1.1 \mathrm{~mm}$ or more and age of patients should be $9-16$ years for REPs. Estefan et al. demonstrated greater root maturation in patients aged 9 to 18 years and having apical diameter larger than 1 $\mathrm{mm} .{ }^{8}$ Our both cases matched the criteria of AAE for REPs.

Success of REPs mainly depends upon the disinfection of the canal system. $\mathrm{AAE}^{6}$ recommends use of $20 \mathrm{~mL}$ of $1.5 \%$ sodium hypochlorite $(\mathrm{NaOCl})$ followed by saline or $17 \%$ ethylene diamine tetra acetic acid (EDTA) $(20 \mathrm{~mL} / \mathrm{canal}, 5$ min) for irrigation and the position of needle should be $1 \mathrm{~mm}$ away from the apex for minimizing cytotoxic effect on stem cells in the apical tissues. As apical diameter has greater dimensions, chances of extrusion of irrigant cannot be ruled out, so we decided to use normal saline in both cases which is chemically inert and biocompatible.

For complete disinfection of the canal, triple antibiotic paste was used. Triple antibiotic paste consist of $1: 1: 1$ ciprofloxacin : metronidazole : minocycline mixed with propylene glycol. When used alone, it is not much effective against the bacteria present in the root canal as well as in apical lesions whereas triple antibiotic paste sterilizes the canals ${ }^{9,10}$ and creates better environment for increase in thickness of root dentine wall and length. ${ }^{11}$

Minocycline, a second generation, semi - synthetic tetracycline has shown to inhibit collagenases and matrix metalloproteinase, non-cytotoxic and increases the level of interleukin-10, an anti-inflammatory cytokine. ${ }^{12}$ 
Metronidazole and Ciprofloxacin initiates formation of new fibroblasts.

But the drawback or side-effect of this paste is that bacterial resistance may develop, and it causes tooth discolouration.13,14 This discolouration is caused by minocycline which binds with calcium ions present in the dentinal tubules forming insoluble chelates. ${ }^{15,16}$ Replacing minocycline with cefaclor or amoxicillin or by placing TAP by retrograde method and restricting it till cervical one third of the root can eliminate or reduce the discolouration. ${ }^{17,18}$

Other reason for discolouration can be use of mineral trioxide aggregate which is the most commonly used material as an intracanal barrier.6,19 But Reynold ${ }^{18}$ has suggested application of resin bonding agent to seal the coronal dentin wall prior to application of the triple antibiotic paste or placing antibiotics paste in retrograde manner using 20 gauge needle which will minimize the contact with the crown of tooth thus averting the probability of discoloration. ${ }^{18}$

We replaced minocycline in TAP with amoxicillin and used white MTA in our both cases. This same observation was reported by other authors too. $20-24$

Use of bonding agent to block the dentinal tubules does not completely eliminate the discoloration but minimizes the severity. ${ }^{25}$ In both of our cases, use of bonding agent could not eliminate discoloration.

Bowel ${ }^{26}$ observed that Vitamin $\mathrm{C}$ addition into the TAP can block the discolouring effect of minocycline in animal model, which needs in vivo evaluations. ${ }^{26}$ Radovan Žižka et al. ${ }^{27}$ addition of antioxidant in TAP during REPs to eliminate discolouration requires clinical confirmation.

Other complication was collapse of mineral trioxide aggregate into the root canal in first case. After 12 months of follow-up, first case showed collapse of MTA radiographically. But tooth was asymptomatic and increase in root dentin length and thickness was present so no further intervention was done. [Fig.1b] At follow up of 18 months, radiographic evaluation revealed closure of apical foramina along with increase in thickness and length of root dentin. Same complication was reported by Dabbagh Basma et al. ${ }^{24}$ This can be prevented by use of collagen matrix. ${ }^{20}$

Success of regenerative endodontic can be measured clinically, radiographically, and histologically. ${ }^{7}$ Clinically, absence of symptoms like pain, swelling and positive response to electric pulp testing were considered as success. ${ }^{7}$ In our both cases, clinical symptoms were resolved after initiation of endodontic treatment. Second case showed delayed response to electric pulp testing in comparison with adjacent teeth.

Radiographically, increase in root dentin thickness and length was considered as success. In our both cases, during follow up, intra oral periapical (IOPA)s radiographs showed increase in root dentin thickness, gradual increase in root length and reduction in apical diameter, thus indicating radiographic success [Fig 1b, 1c, 1d; Fig 2b, 2c,1d]. When we initiated REPs, both cases were stage - II [Fig. 1a, Fig. 2a] according to Cvek's root development stages but after 36 months follow-up, we could achieve stage - V.[Fig.1d,Fig.1d] All the IOPAs were taken by paralleling angle technique as it is more technique sensitive and results in less distortion of image when compare to bisecting angle technique.

Chen et al. ${ }^{28}$ observed 5 types of responses for teeth treated with REPs. Type 1 where there is increased thickening of the canal walls and continued root maturation. Type 2 where there is no significant continuation of root development with the root apex becoming blunt and closed. Type 3 where there is continued root development with the apical foramen remaining open. Type 4 where there is severe calcification (obliteration) of the canal space. Type 5 where there is a hard tissue barrier formed in the canal between the coronal MTA plug and the root apex.

In our both cases according to Chen et al. observations Type1 responses were obtained [Fig.1d, Fig2d].

The basic aim of maturogenesis was achieved in our both cases by continued root development and apical closure which was confirmed radiographically as well as clinically by absence of signs and symptoms of inflammation.

\section{CONCLUSIONS}

Maturogenesis by inducing blood clot can be achieved easily with instruments available in the clinic thus, making it a more simple and practical approach. In our both cases, continued root length, increase in root dentin thickness and closure of apical foramina were achieved. But complications like discolouration of tooth, fall of scaffold were also observed. Thus, disadvantages associated with REPs should not influence the treatment choice.

Financial or other competing interests: None.

Disclosure forms provided by the authors are available with the full text of this article at jemds.com.

\section{REFERENCES}

[1] Diogenes A, Ruparel NB, Shiloah Y, et al. Regenerative endodontics: a way forward. J Am Dent Assoc 2016;147(5):372-80.

[2] Hargreaves KM, Diogenes A, Teixeira FB. Treatment options: biological basis of regenerative endodontic procedures. J Endod 2013;39(3):S30-43.

[3] Zhang W, Yelick PC. Vital pulp therapy-current progress of dental pulp regeneration and revascularization. Int J Dent 2010;2010:856087.

[4] Garcia-Godoy F, Murray PE. Recommendations for using regenerative endodontic procedures in permanent immature traumatized teeth. Dent Traumatol 2012;28(1):33-41.

[5] Wigler R, Kaufman AY, Lin S, et al. Revascularization: a treatment for permanent teeth with necrotic pulp and incomplete root development. J Endod 2013;39(3):31926.

[6] American Association of Endodontics (AAE). Guidelines for Regenerative procedures 2016.

[7] Cvek M. Prognosis of luxated non-vital maxillary incisors treated with calcium hydroxide and filled with gutta percha. A retrospective clinical study. Endo Dent Traumatol 1992:8(2);45-55.

[8] Estefan BS, El Batouty KM, Nagy MM, et al. Influence of age and apical diameter on the success of endodontic regeneration procedures. J Endod 2016;42(11):1620-5.

[9] Bose R, Nummikoski P, Hargreaves K. A retrospective evaluation of radiographic outcomes in immature teeth 
with necrotic root canal systems treated with regenerative endodontic procedures. J Endod 2009;35(10):1343-9.

[10] Hoshino E, Kurihara-Ando N, Sato I, et al. In-vitro antibacterial susceptibility of bacteria taken from infected root dentine to a mixture of ciprofloxacin, metronidazole and minocycline. Int Endod J 1996;29(2):125-30.

[11] Galler KM, Widbiller M, Buchalla $W$, et al. EDTA conditioning of dentine promotes adhesion, migration and differentiation of dental pulp stem cells. Int Endod J 2016;49(6):581-90.

[12] Hoshino E, Takushige T. LSTR 3 Mix-MP method-better and efficient clinical procedures of lesion sterilization and tissue repair (LSTR) therapy. Dent Rev 1998;666:57-106.

[13] Ferreira MB, Myiagi S, Nogales CG, et al. Time-and concentration-dependent cytotoxicity of antibiotics used in endodontic therapy. J Appl Oral Sci 2010;18(3):259-63.

[14] Huang GTJ. A paradigm shift in endodontic management of immature teeth: conservation of stem cells for regeneration. J Dent 2008;36(6):379-86.

[15] Slots J. Selection of antimicrobial agents in periodontal therapy. J Periodontal Res 2002;37(5):389-98.

[16] Tanase S, Tsuchiya H, Yao J, et al. Reversed-phase ion- pair chromatographic analysis of tetracycline antibiotics: application to discolored teeth. J Chromatogr B Biomed Sci Appl 1998;706(2):279-85.

[17] Kim JH, Kim Y, Shin SJ, et al. Tooth discoloration of immature permanent incisor associated with triple antibiotic therapy: a case report. J Endod 2010;36(6):1086-91.

[18] Reynolds K, Johnson JD, Cohenca N. Pulp revascularization of necrotic bilateral bicuspids using a modified novel technique to eliminate potential coronal discolouration: a case report. Int Endod J 2009;42(1):8492.
[19] Ioannidis K, Mistakidis I, Beltes $P$, et al. Spectrophotometric analysis of coronal discolouration induced by grey and white MTA. Int Endod J 2013;46(2):137-44.

[20] Yasa B, Arslan H, Akcay M, et al. Comparison of bleaching efficacy of two bleaching agents on teeth discoloured by different antibiotic combinations used in revascularization. Clin Oral Investig 2015;19(6):143742.

[21] Akcay M, Arslan H, Yasa B, et al. Spectrophotometric analysis of crown discoloration induced by various antibiotic pastes used in revascularization. J Endod 2014;40(6):845-8.

[22] McTigue DJ, Subramanian K, Kumar A. Case series: management of immature permanent teeth with pulpal necrosis: a case series. Pediatr Dent 2013;35(1):55-60.

[23] Kahler B, Mistry S, Moule A, et al. Revascularization outcomes: a prospective analysis of 16 consecutive cases. J Endod 2014;40(3):333-8.

[24] Basma D, Emanuel A, Dat VD, et al. Clinical complications in the revascularization of immature nectrotic permanent teeth. Pediatr Dent 2012;34(5):414-7.

[25] Shokouhinejad N, Khoshkhounejad M, Alikhasi M, et al. Prevention of coronal discoloration induced by regenerative endodontic treatment in an ex vivo model. Clin Oral Investig 2018;22(4):1725-31.

[26] Bowles WH. Protection against minocycline pigment formation by ascorbic acid (vitamin C). J Esthet Dent 1998;10(4):182-6.

[27] Žižka R, Šedý J, Gregor L, et al. Discoloration after regenerative endodontic procedures: a critical review. Iran Endod J 2018;13(3):278-84.

[28] Chen MYH, Chen KL, Chen CA, et al. Responses of immature permanent teeth with infected necrotic pulp tissue and apical periodontitis/abscess to revascularization procedures. Int Endod J 2012;45(3):294-305. 